\title{
Gestão da informação e aprendizagem no Instituto Euvaldo Lodi de Minas
} Gerais

Janete Fernandes Silva

Doutora em Educação pela Universidad Del Mar (Chile).Professora da Universidade Federal de Mato Grosso

Luiz Alex Silva Saraiva

Doutor em Administração pela Universidade Federal de Minas Gerais. Professor da Universidade Federal de Minas Gerais

Leopoldo Briones Salazar

Doctor en Ciencias de la Educación pela Pontificia Universidad Católica de Chile. Professor da Universidad del Mar (Chile)

http://dx.doi.org/10.1590/1981-5344/1787

Neste artigo, analisa-se a gestão da informação no IEL/MG, bem como sua contribuição para o aprendizado individual e coletivo na organização. Trata-se de um estudo de caso qualitativo, concretizado por meio de entrevistas com gerentes que atuam em campos distintos, como inteligência estratégica, economia industrial, inovação, relações internacionais e comerciais, capacitação empresarial e estágio empresarial. Identificou-se que, embora esta organização possua infraestrutura física e de pessoal adequadas, a troca de informação não é natural, tampouco padronizada, demandando iniciativas efetivas.

Palavras-chave: Gestão da Informação; Aprendizagem; Conhecimento; Organização.

\section{Information management and learning at Instituto Euvaldo Lodi of Minas Gerais}

In this paper we analyze information management at IEL/MG, as well its contribution to individual and collective 
learning in organization. That's a qualitative case study, made through interviews with managers who work in different areas, as strategic intelligence, industrial economy, innovation, international and comercial relations, business capacitation and business stage. We identified that although this organization have adequate physical and personeel infrasctructures, information change is not natural or standardized, which demands effective initiatives.

\section{Keywords: Information management; Learning;} Knowledge; Organization.

Recebido em 07.05.2013 Aceito em 12.02.2014

\section{Introdução}

Neste artigo, o objetivo é analisar a gestão da informação e sua contribuição para o aprendizado individual e coletivo no Instituto Euvaldo Lodi de Minas Gerais (IEL/MG). Essa iniciativa se insere em um esforço mais amplo, de discutir os problemas no entorno da informação, principalmente no que se refere a sua qualidade, precisão e confiabilidade. Em um cenário marcado por um grande volume de informações na World Wide Web, observa-se que sua fluidez vem acompanhada pelo esvaziamento de seu valor agregado, o que endereça às organizações a tarefa de alinharem a gestão da informação às práticas cotidianas. A questão é que muitas empresas adotam sistemas de controle da informação que concorrem com outros sistemas empresariais, como os de produção, finanças, recursos humanos, por exemplo, o que leva os empregados optarem por um, em detrimento do outro. Isso leva à perda de energia, de aprendizado e de competitividade.

A falta de processos definidos e incorporados por todos os trabalhadores dificulta a dinâmica de gestão da informação e da aprendizagem no ambiente organizacional, uma vez que empresas pouco integradas tendem a ser menos competitivas que seus concorrentes. A definição de processos é uma necessidade, uma vez que eles descrevem a estrutura e o ambiente de uma organização e como ela realiza e gerencia suas atividades. Assim, ter processos que consolidam a gestão da informação é condição para a captura do conhecimento que se encontra retido com o indivíduo. Davenport (2002, p. 50) corrobora com essa ideia, ao sustentar que o processo de gestão da informação é "entendido como um conjunto estruturado de atividades que incluem o modo como às empresas identificam as necessidades informacionais, obtém, distribuem e usam a informação". Ter os processos mapeados, registrados e documentados, apesar de complexo, facilita o trabalho e o desempenho profissional. 
Não é simples gerenciar informações de terceiros - clientes, concorrentes, prestadores de serviços, fornecedores, parceiros, etc. porque, na maior parte do tempo, elas não estão disponíveis. Tampouco gerenciar relacionamentos interpessoais, tanto por conta de aspectos como a rotatividade e o absenteísmo de trabalhadores quanto por elementos culturais, que podem dificultar a gestão da informação e de aprendizagem. Processos de comunicação com problemas também podem conduzir a decisões equivocadas e prejuízos organizacionais variados. Investimentos restritos em tecnologia podem inviabilizar processos inovativos. Além disso, gestores com baixa capacidade de liderança podem tomar decisões e gerenciar processos de forma insatisfatória quanto aos resultados.

Algumas das dificuldades associadas à implantação de projetos de gerenciamento do conhecimento explícito sugerem que o processo é complexo. Demandam algo de médio a longo prazo para serem incorporados por todos na organização. Apesar de não haver fórmulas, a gestão da informação voltada para o negócio, proporcionando um ambiente de estímulo ao aprendizado individual e coletivo e com foco no compartilhamento de ideias, parece ocorrer apenas quando há alinhamento com a estratégia. Nesse quadro, todos os níveis da organização precisam de clareza quanto aos processos, da determinação da necessidade ao uso da informação, sendo necessários bom senso, coerência, análise crítica, visão sistêmica e espírito de equipe, para a efetividade da gestão de informação, para além da mera gestão de documentos.

Após esta breve introdução, serão apresentados os procedimentos metodológicos do estudo, que precederão discussões teóricas sobre a relação entre informação e aprendizagem e processo decisório. Tal suporte teórico será, em seguida, cotejado com a análise do caso do Instituto Euvaldo Lodi de Minas Gerais. Em seguida, serão apresentadas as considerações finais.

\section{Metodologia}

Para a realização do estudo, adotou-se o estudo de caso como técnica principal de pesquisa, o que possibilitou a análise de uma unidade gerencial, enfatizando os fatores de desenvolvimento em relação ao ambiente. Yin (2005, p. 32) compreende o estudo de caso como "uma investigação empírica que investiga um fenômeno contemporâneo dentro de seu contexto, especialmente quando os limites entre eles não estão claramente definidos". Esse trabalho adota um delineamento pluralista, de complementaridade entre perspectivas $e$, por isso, a escolha pelo estudo de caso se deu por ele não ser caracterizado pela simplicidade, o que é adequado para lidar com a temática em tela. Priorizou-se a abordagem qualitativa, por permitir melhor entendimento dos fenômenos investigados. Merriam (1998) considera essa junção de modalidades de "pesquisa de estudo de caso qualitativo", tendo sido possível analisar a gestão da informação e sua contribuição para o aprendizado individual e 
coletivo no IEL/MG, considerando suas múltiplas dimensões, inclusive o inter-relacionamento entre suas áreas.

Foi traçado um caminho basicamente descritivo na definição dos procedimentos para a coleta dos dados. Não se buscou, portanto, chegar a uma posição conclusiva sobre o fenômeno em foco. $O$ instrumento de coleta de dados precisava apresentar características que captassem o significado atribuído pelos entrevistados a cada ponto a eles apresentado. Para tanto, foi elaborado um roteiro semiestruturado de entrevistas, por ser mais apropriado para abordar os indivíduos sobre a temática. Todas as entrevistas, obtidas por meio de encontros pessoais e individuais com cada um dos entrevistados, conforme agendamento prévio, foram integralmente gravadas e transcritas. Os sujeitos de pesquisa foram seis gerentes do IEL/MG, correspondendo a todos os gerentes sediados em Belo Horizonte, sendo excluídos os gerentes do interior de Minas Gerais.

A análise em profundidade, a intencionalidade e a busca pela compreensão da realidade fazem com que a análise do estudo de caso qualitativo se restrinja aos elementos no caso, não cabendo nenhuma extensão da análise ou das conclusões. Contudo, ainda que não seja possível metodologicamente extrapolar os dados, a análise pode se assemelhar a de outros casos, a que este estudo não pode se furtar, como colocado por Saraiva (2009): transposições analíticas podem ser eventualmente feitas, considerando que se trata de um caso composto por subcasos, relacionados às interfaces entre aprendizagem e informação no ambiente organizacional.

\section{Informação, aprendizagem e processo decisório}

Nas últimas décadas, as organizações vêm passando por várias mudanças, devido à dinâmica do mundo dos negócios. Por isso, tiveram que redefinir processos e foco de atuação, tendo investido em novas tecnologias, sistemas de conectividade e integrado à gestão, na busca de se manterem em um mercado crescentemente competitivo. Nesse quadro, a atenção se volta para a informação, matéria-prima para decisões em todos os níveis da organização. Gerenciar as informações internas e externas nesse ambiente é algo estratégico. Davenport e Prusak (2003) defendem que a gestão do conhecimento ${ }^{1}$ pode ser uma coleção de processos voltados para a determinação das necessidades e demandas; tratamento; disseminação; e utilização do conhecimento para o alcance da meta e dos objetivos organizacionais. Todo processo de gestão organizacional, principalmente o do conhecimento explícito, se apoia na tríade pessoas, tecnologias e processos (SILVA, 2000).

Para Davenport e Prusak (2002, p. 6), conhecimento é "uma mistura fluida de experiência condensada, valores, informação contextualizada e insight experimentado, o qual proporciona uma estrutura para a avaliação e incorporação de novas experiências e informações". Nonaka e Takeuchi

\footnotetext{
${ }^{1}$ Neste trabalho, entende-se como gestão do conhecimento o gerenciamento do conhecimento explícito, por não se acreditar na possibilidade de gerenciamento do conhecimento tácito. A conversão do conhecimento tácito em explícito é passível de gerenciamento, por ser processual.
} 
(1997) definem a gestão do conhecimento como a capacidade de criar novos conhecimentos, disseminá-los e incorporá-los em processos produtos e serviços - devendo ser uma "memória organizacional" que possibilita o acesso ao conhecimento existente na organização como um todo e em cada um dos seus membros, em particular. Nesse movimento de troca de conhecimentos, a cultura organizacional determinará até onde o indivíduo e os grupos poderão contribuir de forma inovativa para o negócio da organização.

A organização que gerencia seus conhecimentos alcança resultados vantajosos no mercado. A criação do conhecimento organizacional depende de condições que permitam às organizações realizarem a conversão entre conhecimento tácito em explícito e vice-versa. 0 conhecimento é um processo de justificar a crença individual dirigida à verdade. Para Nonaka e Takeuchi (1997, p. 62):

O processo dinâmico no qual a organização cria, mantém e explora o conhecimento é muito similar ao padrão dialético. 0 conhecimento também é criado dinamicamente, sintetizando o que aparenta serem opostos e contradições. É criado através de uma espiral que passa através de dois conceitos aparentemente opostos, como tácito e explícito, caos e ordem, micro (individuo) e macro (ambiente), eu e outro, mente e corpo, parte e todo, dedução e indução, criatividade e controle, inferior e superior, burocracia e força de trabalho, e assim por diante. A chave para liderar o processo de criação do conhecimento é o raciocínio dialético, que transcende e sintetiza essas contradições.

A dialética tem como característica fundamental a contradição. A positividade se realiza por meio da negatividade, bem como a tese, da antítese, o que constitui um processo importante para a aquisição e compartilhamento do conhecimento. Ela foi utilizada por Sócrates para buscar a verdade, justificar a crença, debatendo as contradições, fazendo brotar a contradição entre frases para encontrar a verdade. A dialética designou sucessivamente a busca de uma definição verdadeira, mediante divisão de gêneros e espécies e sua conexão; o diálogo conduzido com breves perguntas e respostas; a busca intersubjetiva; o argumentar, preponderantemente em um campo em que não se possa proceder de forma rigorosa com base em premissas demonstradas como verdadeiras ou tomá-las intuitivamente como tal e em que, pelo contrário, podem ser assumidas apenas como prováveis. Partindo da visão dialética, em que aparentemente conhecimento explícito se opõe ao conhecimento tácito, Nonaka e Takeuchi (1997, p. 38) justificam a importância da gestão do conhecimento na organização, desde o momento que essa precisa converter conhecimento em inovação e em processo competitivo:

A pedra fundamental da nossa epistemologia é a distinção entre o conhecimento tácito e o explícito [...]. e que o segredo 
para a criação do conhecimento está na mobilização e conversão do conhecimento tácito. E como estamos preocupados com a criação do conhecimento organizacional, em oposição à criação do conhecimento individual, nossa teoria também terá sua própria 'ontologia', preocupada com os níveis de entidades criadoras do conhecimento individual, grupal, organizacional e interorganizacional.

Segundo o enfoque antropológico do conhecimento, o homem só aprende o que the permite a sobrevivência e a diferenciação em um dado grupo social. Nesse sentido, é relevante ressaltar que a dimensão antropológica é referenciada por Nonaka e Takeuchi (1997) como a segunda dimensão da criação do conhecimento, denominada de ontológica. Segundo os autores, o conhecimento parte dos indivíduos para as comunidades de interação, atravessando os níveis e fronteiras interorganizacionais, o que permite, sem esforço adicional, uma analogia com a questão do conhecimento compartilhado pelo grupo, ou antropologia cognitiva, e com os significados compartilhados, conceitos e codificação do conhecimento, que designam a antropologia simbólica.

Morin (1996, p. 191) descreve condições antropológicas do conhecimento, destacando que o "conhecimento espiritual é o conhecimento propriamente humano". Ele seria a emergência última de um desenvolvimento cerebral, no qual acaba a evolução biológica da hominização e começa a evolução cultural da humanidade. A dimensão antropológica permite identificar, no indivíduo, os indutores da motivação, tendo, como referência primária, o conhecimento capaz de gerar vantagens comparativas pessoais, isto é, capaz de gerar diferenciação entre os indivíduos, atribuindo-Ihes uma condição competitiva mais favorável. Esse processo corresponde a uma curva de evolução associada à visão do trabalho ao longo da história da industrialização.

Integra essa perspectiva a dimensão epistemológica, também conhecida como teoria do conhecimento ou filosofia da ciência. Por meio da epistemologia, foi possível emergir a distinção de Polanyi (1966) entre o conhecimento tácito, decorrente da experiência de vida, associado à percepção e intuição e, portanto, pessoal e de difícil transferência; e o conhecimento explícito ou codificado, que pode ser descrito por meio da linguagem formal, sistemática e informal. A epistemologia é uma das duas dimensões de referência para criação do conhecimento, segundo Nonaka e Takeuchi (1997).

Davenport e Prusak (2003) defendem que a criação do conhecimento é compreendida por duas dimensões, uma no nível do indivíduo e outra, no social. A primeira explicita que a ideia de que o conhecimento é individual e sua construção é subjetiva e una, podendo ser inferida a partir dos comportamentos e resultados da acumulação das próprias experiências. A segunda dimensão ocorre na construção social, no sentido em que esse resulta da interação entre o indivíduo e o grupo social e suas circunstâncias (SILVA, 2000). Diante do exposto, pode-se 
dizer que a conversão da informação (conhecimento explícito) em conhecimento tácito é algo individual e próprio ao ser humano. Assim, ninguém terá acesso ao processo de conversão até que o indivíduo codifique - em linguagem, símbolos e imagens - o que deseja comunicar. Nada impede que a informação que está acessível ao grupo promova a geração de novos conhecimentos e, novamente, eles sejam socializados. Reforça-se que, enquanto o conhecimento permanecer com o indivíduo, de modo que não explícito, isto é, não compartilhado e não disseminado, os membros da organização não conseguirão multiplicar o valor do seu significado e de sua imagem.

É importante destacar que a formalização do conhecimento individual pode impedir o processo de aprendizado e de criatividade no momento em que o indivíduo acumula informações, experiências, valores e um modo de vida peculiar, pois pode haver certa dificuldade de externalizar sua visão sobre o objeto ou contexto em questão. No momento em que ele não relaciona esse modo de vida ao ambiente externo, pode haver uma estagnação da aprendizagem, pois ele não recebe o estímulo para agir cognitivamente, impedindo a geração de novos conhecimentos ou novas ações.

Pensada em um gráfico tridimensional, é possível visualizar a espiral do conhecimento de Nonaka e Takeuchi (1997), na qual, no nível epistemológico, o conhecimento emerge para cima, enquanto no nível ontológico, move-se da esquerda para a direita e novamente para a esquerda em movimento cíclico e contínuo. A dinâmica organizacional ocorre por meio do movimento cíclico e contínuo do conhecimento, permitindo a representação e a interação das duas espirais durante todo o tempo.

Entretanto, há, também, a dimensão da práxis. Uma posição kantiana, apresentada por Crampe-Casnabet (1994, p. 154), que amplifica o sentido original do termo, aprofundando a percepção de que, por trás de uma ação, mais do que comando, "existe um código de ética e conduta, a ser desvendado e apreendido". Deve-se entender por prática uma operação, uma ação, em vista da realização de um fim que um indivíduo representa para si, assim como são representados os meios que Ihe permitem atingir o fim perseguido. Há, para cada prática, uma técnica, que consiste, uma vez desejado um fim, em adaptar os meios adequados a sua realização. Essa prática é empírica, está fora do domínio ético. A práxis se refere ao uso de um conjunto de saberes organizados por meio de um método ou de uma operação, a partir do qual é possível alcançar um resultado. Para atingi-lo, é necessário combinar habilidades técnicas, éticas e sensoriais, como a intuição. Conhecer consiste em unir a forma do conceito e o dado sensível que afeta a sensação. Assim, já que o sujeito não pode gerar por vontade própria a matéria de um objeto, todo o conhecimento começa com a experiência (CRANPE-CASNABET, 1994).

Morin (1996, p. 192) complementa que o conhecimento humano é, na sua origem e no seu desenvolvimento, inseparável da ação; como todo conhecimento cerebral, ele elabora e utiliza estratégias para resolver problemas postos pela incerteza e incompletude do saber. A práxis refere- 
se ao exercício empírico que, apesar disso, não dispensa o aprendizado formal. A prática permite uma associação entre conhecimento lógicoformal, ou explícito, e a experiência vivenciada, ou, ainda, conhecimento tácito e a intuição. Há, contudo, que se considerar a percepção sobre a sociedade que se utiliza do conhecimento, quando esse conhecimento pode transformar essa sociedade.

A gestão do conhecimento, entenda-se, aqui, como a do conhecimento explícito, é a aquisição, a troca e o uso da informação no contexto das organizações, incluindo os processos de gestão e os sistemas de informação, requerendo a transformação do conhecimento individual em conhecimento coletivo, de forma a ser compartilhado e apropriadamente aplicado nas atividades das organizações. Portanto, ocorre a partir da aprendizagem, tornando-se um momento cíclico para que os novos conhecimentos surjam, exigindo do contexto da organização atitudes que transcendem o processo de aprendizagem individual para 0 coletivo e que seja contínuo. Para Saban et al. (2000), a aprendizagem individual pode ser considerada, portanto, no âmbito das organizações, o nível individual da aprendizagem coletiva.

Percebe-se que o aprendizado individual é condição necessária, mas não suficiente para a inteligência da organização. Corroborando com essa visão, Sweringa e Wierdsma (1995) salientam que a aprendizagem individual é necessária, mas não suficiente para o aprendizado coletivo. 0 fator crucial, ponderam Boyett e Boyett (2003), reside na eficácia com que os indivíduos compartilham o saber nos níveis administrativos da organização. Tendo em vista que a aprendizagem resulta da relação do indivíduo com o meio, ela é importante na dinâmica organizacional.

Maturana (1998) assume a aprendizagem como um processo contínuo de mudanças de comportamento, induzido pela necessidade de um acoplamento estrutural entre indivíduo e meio. A aprendizagem corresponde às mudanças ocorridas ao longo da vida em função de uma rede de interações com os outros e com o meio, que se orienta para a adaptação em face de demandas recorrentes. Nesse processo histórico, tanto se dá a (re)produção do indivíduo quanto do meio. A aprendizagem, como a cognição, está orientada para o fazer. Aprender é mudar para fazer. Aprender é fazer. Nesse contexto interpretativo, o discurso sobre planejamento como aprendizagem remete à contínua necessidade de repercepção de situações para a delimitação de ações. Como Matus (1993, p. 12) afirma, "o fenômeno do planejamento é a mediação entre o conhecimento e a ação".

Para Fleury e Fleury (1998, p. 20), o processo de aprendizagem em uma organização "não só envolve a elaboração de novos mapas cognitivos, que permitem compreender melhor o que está ocorrendo em seu ambiente externo e interno, como, também, a definição de novos comportamentos, que comprovam a efetividade do aprendizado". Os autores defendem pressupostos que orientariam as empresas e que poderiam dar sustentação ao processo de aprendizagem, destacando: a ação estratégica, a integração dos processos de decisão, a definição de 
políticas de recursos humanos que apoiem e impulsionem a aprendizagem e o desenvolvimento de uma cultura de aprendizagem.

Caravantes e Pereira (1985, p. 6) afirmam que esse é um "processo de aquisição da capacidade de usar o conhecimento, que resulta da prática e da experiência e que produz uma mudança relativamente permanente no comportamento". Para Kolb (1984; 1971), a aprendizagem é um processo em que o conhecimento é criado por meio da experiência. Ele considera que o modelo de como as pessoas aprendem, modelo vivencial, é um ciclo quadrifásico, composto de quatro tipos de habilidades: experiência concreta, observação reflexiva, conceituação abstrata e experimentação ativa. Observa-se que a aprendizagem, na visão dos autores, pode ser analisada como um processo de mudança, provocando estímulos diversos, acompanhados por emoções, e que pode refletir em mudanças no comportamento dos indivíduos. É percebido que o processo de aprendizagem passa por três ciclos distintos: (1) as regras que se referem ao que se deve e pode fazer, (2) insight que se relaciona com o que se sabe e com o que se compreende e (3) os princípios que focam no que é e no que se deseja ser. O obedecer a esse ciclo acontece quando na aprendizagem ocorre a indagação/questionamento e discussão dos princípios essenciais sobre os quais a organização está alicerçada (ESTIVALETE; LÖBLER; PEDROZO, 2006).

A aprendizagem, no contexto organizacional, pode ser considerada como uma resposta a mudanças enfrentadas pelas organizações, uma vez que se busca desenvolver a capacidade de aprender continuamente, baseando-se nas experiências organizacionais, e traduzir tais conhecimentos em práticas que contribuam para um desempenho melhor. Trata-se de uma aprendizagem estritamente instrumental. Portanto, assume como pressuposto $o$ desenvolvimento de estratégias $e$ procedimentos a serem continuamente construídos para se atingir melhores resultados, contando com a participação efetiva dos indivíduos no processo de aquisição e disseminação de informações. Essa condição se relaciona à questão do desenvolvimento de competências, havendo uma cumplicidade entre as abordagens apresentadas e uma carência no que se refere à explicitação dessa relação (BITENCOURT, 2001, p. 62).

Alguns, como Kolb (1971), Senge (1990), Argyris (1977) e LeonardBarton (1995), desenvolveram trabalhos sobre o desenvolvimento de competências gerenciais ${ }^{2}$. Kolb enfocou o desenvolvimento do ciclo de aprendizagem baseado na vivência, uma visão processual que destaca a importância da ação e da reflexão em um processo contínuo, que visa a equilibrá-las. Senge (1990) desenvolveu disciplinas que sustentam sua visão e trata da questão da competência indiretamente. Para ele, o domínio pessoal pode ser interpretado como uma necessidade de desenvolver as pessoas, tendo como base o autoconhecimento. Argyris

\footnotetext{
${ }^{2}$ É tudo o que o indivíduo precisa saber para desempenhar suas funções gerenciais como gestor. Também é necessário demonstrar qual o seu diferencial competitivo e o impacto em seus resultados, como criatividade, flexibilidade, proatividade, etc. Competência se diferencia de habilidade, por esta última se restringir ao saber fazer (FLEURY; FLEURY, 1997).
} 
(1977) dedicou-se à discussão da lacuna observada entre a teoria assumida e aquela em uso - discurso e prática. Nesse ponto, ressalta-se a necessidade de tratar as competências como práticas observadas no ambiente de trabalho, fato esse que a diferencia do desenvolvimento de potencial. A necessidade de refletir sobre o processo de desenvolvimento de competência a partir do erro e, assim, favorecer o desenvolvimento do double loop lerarning, é outro ponto tratado pelo autor.

Leonard-Barton (1995) defende que a competência deve ser vista como um sistema, sendo difícil pensar apenas em competências individuais, uma vez que os indivíduos estão em constante processo relacional. Afirma que os procedimentos formais e informais são fundamentais para a interação humana e servem de base para a construção de competências. Vinculado a essa abordagem, o processo de aprendizagem se apoia em diferentes concepções. Os estudos de Argyris e Schön (1978) sobre aprendizagem de single loop (ciclo único) e double loop (ciclo duplo), marcaram sua importância na teoria das organizações. Eles as diferenciam, afirmando que a primeira - a aprendizagem de ciclo único - refere-se ao como fazer as coisas melhor, por meio da experiência, e exerce impacto sobre parte da organização. A segunda trata do porquê das coisas serem feitas, gerando efeitos e impactos de longo prazo, aludindo a mudanças mais radicais e tendo como objetivo o desenvolvimento de novos paradigmas, envolvendo o questionamento dos valores fundamentais da organização (ESTIVALETE; LÖBLER; PEDROZO, 2006).

Morgan (2000) corrobora os estudos dos autores, afirmando que a aprendizagem, denominada por ele de circuito único, apoia-se na habilidade de detectar e corrigir o erro com relação a dado conjunto de normas operacionais. De acordo com ele, muitas organizações se tornam proficientes na aprendizagem de circuito único, desenvolvendo a habilidade de examinar o ambiente, de estabelecer objetivos e de monitorar o desempenho geral do sistema em relação a esses objetivos. Essa habilidade básica é, na maioria das vezes, institucionalizada sob a forma de sistemas de informação, planejados para manter a organização em curso. Para que ocorra o aprendizado de circuito duplo, é preciso ser capaz de se "olhar duplamente" a situação, questionando a relevância das normas de funcionamento. Todavia, a habilidade de atingir proficiência em termos de uma aprendizagem de ciclo duplo usualmente é de mais difícil planejamento. Afirma que, enquanto algumas organizações têm sido bemsucedidas, institucionalizando sistemas que reveem e desafiam normas básicas, políticas e procedimentos operacionais em relação a mudanças que ocorrem nos seus ambientes - encorajando o debate contínuo e a inovação - muitas falhas surgem ao colocá-los em prática. É possível, assim, verificar esse problema tanto em organizações burocráticas quanto em não burocráticas, uma vez que os princípios habitualmente operam de maneira que realmente obstruem o aprendizado do indivíduo. Para Morgan (2000), à medida que os indivíduos são responsáveis pelos seus desempenhos em um sistema que recompensa o sucesso e pune as falhas, têm um incentivo para se engajarem em várias formas de fraudes 
para se proteger. Para ele, se os sistemas de imputabilidade fomentam esse tipo de defesa, uma organização raramente será capaz de tolerar altos níveis de incerteza.

Outro aspecto a ser lembrado são os membros da organização, que tentam abordar os problemas de forma retórica ou com racionalizações que transmitem a impressão de que sabem aquilo que estão fazendo. Morgan (2000) julga que esse posicionamento pode não ser não apenas para impressionar os outros, mas, também, para convencê-los de que tudo vai bem e que possuem a habilidade de lidar com o problema. Reforçam essa posição, engajam-se em comportamentos de disfarce, quando veem surgir ameaças a um modelo básico de prática que leva um indivíduo a desviar a culpa para outro lugar e a prender-se àquela prática, intensificando-a, em lugar de questionar a sua natureza e os seus efeitos. Tais circunstâncias contribuem para não enfrentar as realidades e lidar com elas. Tal dificuldade pode ser mascarada com processos sociais, tais como "pensamento de grupo", que são conjuntos mentais desenvolvidos sobre bases de reforço social, que são frequentemente muito difíceis de romper. Os membros podem desenvolver visões que os impedem de compreender os problemas. A aprendizagem de circuito duplo requer que se reduza o hiato entre a teoria e a realidade, "de tal forma que se torne possível desafiar os valores e as normas embutidas nas teorias utilizadas, assim como aquelas que são adotadas" (MORGAN 2000, p. 95).

Considera-se, neste artigo, que o indivíduo constrói seu processo de conhecimento, dominando-o a partir da aprendizagem e do contexto ambiental em que está inserido. O aprendizado possui várias manifestações cognitivas e comportamentais, que podem emergir na vida do indivíduo em intervalos de tempos diferentes e/ou simultaneamente. Os elementos que transitam no processo de aprendizagem fazem parte das manifestações individuais e são elas que conferem "vida" às organizações. Por isso, não se considera a organização como aprendiz, porque não se acredita nela como uma unidade pensante com insights, que cria mapas cognitivos, que gera e acumula conhecimento. Apenas os seres humanos são capazes de agir cognitivamente e possuir sistemas de armazenamento e de processamento. A organização não tem vida própria, nada faz, toma emprestada a dinâmica social que existe em suas dependências: ainda que se destaquem objetivos coletivos, não é a organização que os possui ou que "age"; são os indivíduos e grupos que levam a cabo tais processos (SARAIVA, 2009).

\section{Informação, conhecimento e aprendizagem no Instituto Euvaldo Lodi de Minas Gerais}

O tratamento das entrevistas permitiu que se chegasse a três categorias finais de conteúdo, material que será sistematicamente tratado nessa seção. São elas: a) informação como matéria-prima para decisão e ação; b) possibilidades e limitações das práticas de gestão do conhecimento; e c) desafios do conhecimento tácito. 


\subsection{Informação como matéria-prima para decisão e ação}

Quadro 1 - Processo de derivação da categoria final de conteúdo: informação como matéria-prima para decisão e ação

\begin{tabular}{|c|c|c|}
\hline Categorias iniciais & Ideias-chave & Categoria final \\
\hline $\begin{array}{l}\text { - Experiência acumulada é } \\
\text { revertida para empresários } \\
\text { - } \quad \text { A informação afeta o trabalho }\end{array}$ & $\begin{array}{l}\text { A informação é ponto de } \\
\text { partida para todas as ações } \\
\text { gerenciais no IEL/MG, } \\
\text { perpassando qualquer atividade }\end{array}$ & $\begin{array}{l}\text { Informação como matéria- } \\
\text { prima para decisão e ação }\end{array}$ \\
\hline
\end{tabular}

Fonte: Dados da pesquisa.

Com as constantes mudanças no ambiente interno e externo do IEL/MG, a informação tem papel crucial no apoio às estratégias e ao processo de decisão, bem como no controle das operações organizacionais. Sua utilização representa uma intervenção no processo de gestão, podendo, inclusive, provocar mudança organizacional, à medida que afeta os elementos que compõem o sistema de gestão. Esse recurso, importante para o negócio, quando devidamente estruturado, pode integrar as funções das várias unidades, por meio dos diversos sistemas organizacionais. A informação é fonte primária de competitividade, como sinalizado pelos depoimentos:

Informação na minha área é matéria-prima, é básico... Acumulamos muita experiência nos últimos anos e informações que serão fornecidas para os empresários, que subsidiarão futuros estudos, que suportarão as ações e produção da gerência. (Entrevistado 1)

Informação é matéria-prima, princípio para qualquer atividade da minha área. Sem ela, não consigo chegar aos resultados estimados. É algo que afeta o nosso trabalho, sem que consideremos ou percebamos. Informação não é só aquela que vai impactar nisso ou naquilo e daí vamos montar um mapa mental com elas, não é um processo muito natural. (Entrevistado 2)

Eu não consigo tomar nenhuma decisão sem informação, é fundamental. Para justificar uma decisão, tenho que partir das informações que me subsidiaram essa decisão. Hoje, o volume de informações que temos é muito grande, saber quais são fidedignas e confiáveis tornou-se uma maratona para todos nós que trabalhamos com relações internacionais e comerciais. (Entrevistado 3)

Não tem como trabalhar sem informação nos dias de hoje, ela é primordial. E, vou falar sinceramente: sou muito objetiva, muito prática, então, às vezes, deixo a desejar nesse sentido. 
E, cada vez mais, fica clara a importância da informação e que sem o conhecimento é complicadíssimo tomar uma decisão. Como sou responsável pela elaboração do planejamento da minha área, tenho que estar atenta aos detalhes. Para que ele aconteça, tenho que ter todos os dados estruturados e acabo errando por falta de informação e perco tempo tendo que consertar ou tendo que mudar a rota. Ocorre porque, às vezes, não estudei, não busquei todas as informações possíveis, não fui às fontes certas. (Entrevistado 5)

É visível a importância da informação para a execução de atividades e para a tomada de decisão no IEL/MG. Na fala dos gerentes, a informação é matéria-prima para o desenvolvimento de tarefas, das mais simples às mais complexas. A informação, ao ser convertida em conhecimento e esse em ações estratégicas, em inovações e em um novo posicionamento do indivíduo diante de situações diferentes, pode ser considerada o processo de conversão e transformação. Sinaliza-se a importância de considerar os diferenciais que estão no entorno dos termos dado, informação e conhecimento, não podendo ser vistos como sinônimos. Davenport e Prusak (2003, p. 1) reforçam essa colocação, dizendo que "o sucesso ou o fracasso organizacional pode depender de se saber de qual deles precisamos, com qual deles contamos e o que podemos ou não fazer com cada um deles".

A compreensão e o entendimento do que são esses três elementos são essenciais para a realização bem-sucedida do trabalho ligado ao conhecimento. É igualmente importante para essa realização a passagem de um elemento a outro. Nas organizações, a codificação converte o conhecimento em formatos acessíveis e aplicáveis. Equipe de trabalho e clientes do conhecimento podem categorizá-lo, descrevê-lo, mapeá-lo, modelá-lo, estimulá-lo e inseri-lo em regras e procedimentos, segundo a conversão do conhecimento defendida por Nonaka e Takeuchi (1997). Cada um desses possui seu próprio conjunto específico de valores e limitações e pode ser aplicado isoladamente ou de forma combinada (Davenport e Prusak, 2003, p. 83).

\subsection{Possibilidades e limitações das práticas de gestão do conhecimento}

Quadro 2 - Processo de derivação da categoria final de conteúdo: possibilidades e limitações das práticas de gestão do conhecimento

\begin{tabular}{|c|c|c|}
\hline Categorias iniciais & Ideias-chave & Categoria final \\
\hline $\begin{array}{l}\text { - } \quad \text { A gestão do conhecimento é } \\
\text { um ponto fraco } \\
\text { - } \quad \text { A modernização da gestão } \\
\text { passa pelo rápido } \\
\text { compartilhamento de informações }\end{array}$ & $\begin{array}{l}\text { - A descontinuidade das ações } \\
\text { afeta a gestão do conhecimento } \\
\text { - As práticas de conhecimento } \\
\text { deveriam ser integradas para gerar } \\
\text { resultados melhores }\end{array}$ & $\begin{array}{l}\text { - Possibilidades e limitações das } \\
\text { práticas de gestão do } \\
\text { conhecimento }\end{array}$ \\
\hline
\end{tabular}

Fonte: Dados da pesquisa. 
A gestão do conhecimento é um ponto fraco no IEL. Eu me lembro bem do trabalho iniciado no passado sobre gestão do conhecimento que não foi para frente. Começamos um trabalho na tentativa de transformar conhecimento tácito em conhecimento explícito, na parte de elaboração de projetos. Contratamos um consultor para formalizar tudo em processo, foi feito um manual - com fluxo de trabalho, com passos para gerenciar o conhecimento. Gostaria que isso estivesse melhor e que pudéssemos fazer muito mais do que fazemos hoje, porque se acaba focando mais na gestão de processo do que na gestão de pessoas. Observe: se sair duas pessoas aqui da área de inovação hoje, não sei o que vai ser. Estamos construindo manuais, definindo metodologias, todos os processos. (Entrevistado 2)

Observa-se, neste depoimento, que há descontinuidade nos programas de gestão da informação e do conhecimento dentro do IEL/MG, por estar focado exclusivamente nos processos e não no indivíduo, peçachave para a construção de conhecimento. Não se trata, portanto, de não formalização, uma vez que os processos estão bem descritos e estruturados; o que falta é um sistema integrado, que faça a ponte entre o ambiente interno e externo e de trabalhadores envolvidos com o programa e que o coloque em prática. Nesse sentido, o IEL/MG adotou como ferramenta de gestão da informação o sistema Sharepoint para armazenamento e disseminação de informações. Esse sistema encontra-se disponível em todas as gerências, mas não está sendo usado na sua potencialidade. Ele não é empregado, por exemplo, para organizar e disseminar informações e, muito menos, como um canal de aprendizagem. Algumas áreas têm suas próprias bases de dados e a informação é disponibilizada apenas para os membros que dela fazem parte:

Minha área é a responsável pela integração das informações e definição de ferramentas de gestão da informação. Hoje, temos o Sharepoint, que vem facilitar essa integração entre as gerências e está disponível para todos do IEL, que já foram treinados. Conseguimos um avanço em relação ao passado. $\mathrm{Na}$ gerência, conseguimos uma integração boa dos núcleos. Tenho a clareza que o que temos ainda é pequeno, frente ao que eu gostaria de ter dentro do sistema FIEMG. Apesar de ter o sistema implantado, em funcionamento, com todo o mapeamento e levantamento, ainda não está operacional do jeito que gostaríamos. Isto é, com todas as informações integradas, as gerências se relacionando com seus clientes, as demandas sendo respondidas e armazenadas dentro do CRM, ainda estamos caminhando. Temos muitas bases de dados isoladas, portanto, migrar tudo isso, juntar as informações e documentos leva tempo. O ideal é não ter coisas engavetadas, 
no arquivo de fulano, na pasta de sicrano, beltrano, isso diminuiu bastante. (Entrevistado 1)

Precisamos modernizar nosso ambiente de informação. Cada núcleo tem seu banco de informação, que não conversam entre si. Para eu ter um relatório, preciso fazer tudo manualmente ou no Excel, perde-se muito tempo para obter uma informação organizada, sabe, com valor agregado. (Entrevistado 6)

Afirma-se que não há um sistema de informação integrado no IEL/MG e que cada gerência trabalha de forma isolada na organização e no tratamento das suas informações, criando banco de dados fragmentados. Por conseguinte, não há uma ferramenta de informação que facilite o processo de aprendizado. Para os entrevistados, informação é importante, mas não se vê um esforço conjunto na definição de uma metodologia comum, que atenda a todas as áreas. Falta um modelo de gestão da informação para todo o Instituto. A questão que se faz é: como falar de algo mais complexo, que é a gestão do conhecimento, se o básico não está estruturado, implementado e em uso? Resgata-se o argumento de Davenport e Prusak (2003, p. 1): "é preciso saber o que cada um significa e qual o papel no negócio da organização - dado, informação e conhecimento".

A informação tem sua origem na coleta de dados. Estes, por sua vez, são organizados e recebem significado de acordo com o contexto delimitado, determinado pela necessidade ou pela demanda. Eles servirão de base para identificar as informações pertinentes entre as já disponíveis no contexto organizacional. Caso não existam, essas informações serão buscadas em outras fontes fora da organização, transformando-se em ativos estratégicos. (BEUREN; RAUPP, 2003).

Entre as tecnologias de que os gestores dispõem, os sistemas de informações estão entre as mais importantes para atingir altos níveis de eficácia e produtividade nas operações, especialmente quando combinadas com mudanças no comportamento da administração e nas práticas de negócio. Os sistemas de informação se tornaram as principais ferramentas para a criação de produtos e serviços e modelos de negócios inteiramente novos, descrevendo como a empresa os produz, entrega e vende, a fim de obter lucro e vantagem competitiva. Os sistemas de informação são ferramentas indispensáveis para uma eficaz gestão da informação. Atente-se para a necessidade de criação e associação das políticas de informação e de informática dentro da organização. As áreas responsáveis pela elaboração e implementação dessas políticas precisam estar em sintonia para o desenvolvimento adequado de sistemas de informação, que retratem a realidade do contexto organizacional e possam gerar conteúdos informacionais confiáveis. 


\subsection{Desafios do conhecimento tácito}

Quadro 3 - Processo de derivação da categoria final de conteúdo:

Desafios do conhecimento tácito

\begin{tabular}{l|l|l}
\hline \multicolumn{1}{c|}{ Categorias iniciais } & \multicolumn{1}{|c}{ Ideias-chave } & \multicolumn{1}{c}{ Categoria final } \\
\hline \hline - Necessidade de & O conhecimento precisa ser & Desafios do conhecimento \\
sistematização de ações & sistematizado e compartilhado & tácito \\
- É necessária a & como forma de concretizar o \\
descentralização da informação & $\begin{array}{l}\text { compartilhamento como processo } \\
\text { entre os profissionais }\end{array}$ & \\
\hline
\end{tabular}

Fonte: Dados da pesquisa.

A gestão do conhecimento tácito para o explícito é um processo que exige a integração da cultura, dos valores, da percepção dos indivíduos. É preciso envolvimento de todos os membros da organização para a sua ocorrência, principalmente daqueles que estão inseridos no nível estratégico. Ela não ocorre simplesmente porque a organização possui sistemas de informação sofisticados e de última geração, é preciso que todas as pessoas estejam disponíveis a compartilhar suas experiências e que estejam envolvidas com o processo de gestão. Para os entrevistados, no IEL/MG há um esforço nesse sentido, mas ele ainda é frágil:

Temos feito de uma forma até empírica como responder uma demanda [...] Dentro da nossa metodologia de inteligência, temos que definir o plano diretor de coleta e qual a questão a ser trabalhada. Esta atividade é desenvolvida em equipe. Discutimos o tema, o assunto, debruçamos no problema, quais são as questões-chave, qual a necessidade de se montar uma equipe multidisciplinar, a questão pode envolver profissionais de outra gerência e áreas do conhecimento, inclusive definir em quais fontes buscar as informações. Quando o assunto é mais complexo, em um primeiro momento, coletam-se informações para entender o assunto, o tema em questão, o que está sendo abordado, para, depois, sim, elaborar e montar o projeto. São projetos de análise e de inteligência. Essa primeira fase envolve a interação da equipe, discussão e solução. O trabalho é em equipe, às vezes, a coleta é feita por mais de uma pessoa e depois tem que juntar e fazer um trabalho de análise. Pode ocorrer a necessidade de voltar e ter que coletar uma e outra coisa que ficou faltando para complementar. Neste momento, existe um trabalho de interação da equipe [...] (Entrevistado 1)

Na minha área, os colaboradores que saem para um processo de capacitação, de treinamento e de conhecer uma oportunidade de mercado in loco, peço para fazerem uma exposição para 0 restante da equipe ou elaborarem um relatório, quando é algo mais técnico. Vejo que precisa ser 
melhorada essa dinâmica, está fragilizada. Minha opinião é que tinha que ser obrigatória a transferência de informações provenientes de eventos. Sei lá, definir um instrumento ou metodologia de todo o processo - desde a liberação, a saída e a disseminação da informação. No dia a dia, a minha equipe troca informação, discute os problemas e busca soluções, mas existem outros que são mais fechados e têm essa dificuldade de comunicação, mas, por outro lado, fazem com perfeição suas atividades, mas têm dificuldade de compartilhar, de trocar experiências. (Entrevistado 3)

Eu poderia "falar bonito" em teoria para você: o evento o qual a pessoa vai, tem que compartilhar o aprendizado e 0 conhecimento adquirido. Portanto, eu não deixo de pedir para que as pessoas passem um e-mail, façam um sumário ou uma síntese do conteúdo discutido lá, dos principais pontos que ela colheu, que ela absorveu naquele evento em que participou. Vejo como fundamental para o aprendizado coletivo. Em alguns momentos, isso não acontece. Eu não vejo com tanta facilidade o que o indivíduo aprendeu e ver esse aprendizado em forma de resultado, em alguns casos, consigo; em outros, não. Faltou ao gerente cobrar ou ser mais incisivo enquanto a cobrança em relação a essa postura da troca de informação. Às vezes, o colaborador, participante do evento, dá a desculpa que o evento não foi aquilo que ele esperava [...] Então, eu não tenho a menor dúvida que dentro de uma percentagem de pessoas, não estão sendo totalmente compartilhadas e nem democratizadas as informações dentro da área. Precisa melhorar, não tenho dúvidas. (Entrevistado 4)

Verificou-se que, na organização investigada, não há fluxos de informação padronizados que facilitem a comunicação interna e externa. Mas, observou-se uma preocupação por parte dos entrevistados com a definição de uma metodologia e de ferramentas que agilizem a troca e compartilhamento de informações. Apesar da dificuldade de se codificar o conhecimento tácito, seu valor compensa o esforço. O mapeamento do conhecimento em uma organização acaba se constituindo em um inventário do potencial dos ativos estratégicos que essa possui; mas a falta desse mapeamento acaba gerando prejuízos para todos os envolvidos com o contexto organizacional. Desenvolver metodologias que permitam a retenção do conhecimento que se encontra de posse do indivíduo é um passo para a construção de um sistema de informação com valor agregado. Percebe-se que, no IEL/MG, existe a preocupação de reter o conhecimento gerado nas suas dependências, mas há muito ainda a ser feito: 
Estamos dentro da empresa e conhecimento tem que ficar aqui. Isto está sendo estruturado e é uma preocupação do Instituto, a gerência de inteligência estratégica está como responsável por essa atividade. Confesso que sou displicente nesse campo, termino um trabalho e coloco lá no depositório para ser democratizado. Mas, muita coisa fica na cabeça das pessoas. Precisamos aperfeiçoar, na prática está fraca. (Entrevistado 3)

[...] a cada dia estou tentando não deixar conhecimento preso com ninguém. Isso significa que, por exemplo, se uma pessoa tem conhecimento e sabe manipular uma base de dados, outras pessoas têm que ter esse conhecimento. $\mathrm{E}$, às vezes, eu até propositalmente faço um teste. [...] Então, no dia a dia, as demandas surgem para serem respondidas em tempo curto, eu não posso ter conhecimento na posse de apenas uma pessoa, pode gerar um grande problema para área. Percebo que a equipe esta aprendendo e se educando, inclusive eu [...] É preciso que todos tenham conhecimento de tudo e saibam onde encontrar a informação, até mesmo porque temos que fazer a roda girar sem nenhum problema. (Entrevistado 4)

Observa-se que o acesso ao conhecimento só ocorre no IEL/MG, quando o profissional tem interesse em compartilhá-lo, o que pode ocasionar na perda definitiva de informação no momento em que esse trabalhador deixa a empresa, gerando problemas significativos, que ameaçam o valor do capital intelectual da organização. Esse risco sugere a necessidade de estratégias para impedir tais perdas. Uma solução nesse sentido pode ser o compartilhamento do conhecimento por meio de processos de orientação ou programas de aprendizagem - dinâmica de grupo, capacitação, treinamento, diálogos - para que o conhecimento não se concentre em um único indivíduo. Os recursos multimídias e os de hipertexto permitem a captura pelo menos de uma fração do conhecimento do indivíduo.

Alguns estudos apontados por Davenport e Prusak (2003) afirmam que os seres humanos aprendem melhor com histórias. Os indivíduos pensam de forma narrativa, não argumentativa e nem paradigmática, representado a retórica, portanto, importante papel na transmissão do conhecimento. Nos campos analisados, a pesquisa mostrou que o conhecimento é comunicado com mais eficácia por meio da narrativa convincente, elegante e apaixonada.

Das experiências vivenciadas pelos autores, o que se pode dizer é que a informação é componente de estratégia. Seu uso consiste em criar alternativas diferenciadas de estratégias e alertar para a capacidade da empresa ao gerar informação exclusiva sobre 0 contexto de seu 
empreendimento. Contudo, o uso estratégico da informação pode resultar em vantagem competitiva se ela contribuir, efetivamente, para a identificação de alternativas que aperfeiçoem o desempenho do contexto social em todos os níveis. Entretanto, a empresa pode alterar as regras da competição, por meio da mudança de seus processos e da importância que confere à informação. O uso estratégico da informação implica embuti-la em produtos e serviços já existentes na empresa e esse uso pode ajudar na definição do momento em que se deve eliminá-los da linha de produção.

Apesar dos discursos corporativos de que conhecimento do trabalhador é um recurso valioso, a maioria das empresas não despende esforços no sentido de cultivar atividades orientadas para o conhecimento dos seus trabalhadores (DAVENPORT; PRUSAK, 2003). Pode-se dizer que o Instituto tem uma infraestrutura física e humana - técnicos - adequada, o que sugere que isso não é suficiente para torná-lo gestor de conhecimento explícito.

\section{Considerações finais}

A pesquisa realizada sugere alguns elementos. A informação é vista como indispensável para os processos de rotina; é qualificada como um instrumento modificador da consciência humana, isto é, permite uma mudança cognitiva. A informação só permitirá retorno se o indivíduo a percebê-la como matéria-prima primordial para o seu desenvolvimento e do grupo que faz parte. A gestão de informação no IEL/MG é ainda frágil e o processo não está atendendo adequadamente todas as gerências, o que sugere que muito ainda há por fazer, tanto por parte dos gestores quanto por parte dos trabalhadores. Quando ocorre troca de informação, ela se limita ao desenvolvimento de atividades processuais e que, de certa forma, está estruturado dentro de cada gerência, com metodologias distintas de organização, de disseminação e de acesso restrito, apesar de haver um sistema, o Sharepoint, que visa à integração e disseminação das informações para todo o ambiente organizacional.

Os dados sugerem que, para um eficaz processo de gerenciamento de informação, é preciso que a organização possua um processo de comunicação dentro e fora de suas dependências, que seja dinâmico e com o mínimo de ruído possível. São necessários mediadores que facilitem o acesso às informações e que as que forem disponibilizadas apresentem conteúdos com valor agregado e façam diferença no negócio da organização. E, por último, que haja sistemático retorno de quem emite e de quem recebe a informação, de forma a eliminar as eventuais lacunas.

Outro ponto observado é que a transferência de informação é um processo que depende do emissor e do receptor. Esse processo requer informação incorporada em produtos e serviços, factível de comunicação entre grupos de indivíduos, e de um ambiente com características similares que facilite a sua ocorrência. Uma forma de facilitar a transferência de informação é definindo uma política de informação que esteja alinhada à estratégia e que todos tenham conhecimento e a 
coloquem em prática. Essa política precisaria ser um "modelo" aberto, espontâneo e explícito, que oriente os trabalhadores ao alcance de objetivos progressivos e democráticos. Quanto à geração de informação, observou-se que essa é de caráter formal, sistemático, articulado e baseado em regras e sua modelagem é para fins processuais.

A dificuldade encontrada pelos trabalhadores dentro das organizações na criação, na troca, no compartilhamento de informações é visível, por eles serem controladores e egocêntricos por natureza. Apesar de projetarem um discurso inserido na "sociedade do conhecimento", agem a partir de princípios industriais provenientes do início do Século XX. Como bem sinalizado por Morgan (2000), o indivíduo age para impressionar os outros ou para mostrar que sabe o que está fazendo, mascarando a situação atual e continua anos e anos (re)afirmando o erro.

\section{Referências}

ARGYRIS, C. D. Double loop learning in organizations. Harvard Business Review, Boston, v. 55, n. 5, p. 115-125, Sep./Oct. 1977.

ARGYRIS, C., SCHÖN, D. A. Organizational learning: a theory of action perspective. Reading, MA: Addison-Wesley Publishing Company, 1978.

BEUREN, I. M; RAUPP,F. M. Compartilhamento do conhecimento em Incubadoras de empresas: um estudo multicasos das incubadoras de Santa Catarina Associadas à Anprotec. In: ENCONTRO DA ASSOCIAÇÃO NACIONAL DE PÓS-GRADUAÇÃO E PESQUISA EM ADMINISTRAÇÃO, 27., 2003, Atibaia. Anais... Atibaia: ANPAD, 2003.

BITENCOURT, C. C. A gestão de competências gerenciais : a contribuição da aprendizagem organizacional. 2001. 319f. Tese (Doutorado em Administração) - Escola de Administração, Universidade Federal do Rio Grande do Sul, Porto Alegre, 2001.

BOYETT, J. H.; BOYETT, J. T. The guru guides to marketing: a concise guide to the best ideas from today's top marketers. New York: John Wiley \& Sons, 2003.

CARAVANTES, G.; PEREIRA, M. J. L. Aprendizagem organizacional versus estratégia de mudança organizacional planejada: um confronto crítico. Porto Alegre: FAPERGS, 1985.

CRAMPE-CASNABET, M. Kant: uma revolução filosófica. Rio de Janeiro: Jorge Zahar, 1994.

DAVENPORT, T. H. Ecologia da informação. 2. ed. São Paulo: Futura, 2002.

DAVENPORT, T. H. Ecologia da Informação: por que só a tecnologia não basta para o sucesso na era da informação. São Paulo: Futura, 2002.

DAVENPORT, T. H; PRUSAK, P. Conhecimento empresarial: como as organizações gerenciam o seu capital intelectual. Rio de Janeiro: Elsevier, 2003. 
ESTIVAlete, V. F. B.; LÖBleR, M. L.; PEDROZO, E. A. Repensando o processo de aprendizagem organizacional no agronegócio: um estudo de caso realizado numa cooperativa destaque em qualidade no RS. Revista de Administração Contemporânea, Curitiba, v. 10, n. 2, p. 157-178, abr./jun. 2006.

FLEURY, A.; FLEURY, M. T. L. Aprende-se com as empresas japonesas? Estudo comparativo entre empresas brasileiras e mexicanas. Revista de Administração Contemporânea, Curitiba, v. 2, n. 1, p. 7-26, jan. /abr. 1998.

FLEURY, A.; FLEURY, M. T. L. Aprendizagem e inovação organizacional: as experiências de Japão, Coréia e Brasil. São Paulo: Atlas, 1997.

KOLB, D. Individual learning styles and learning process. Cambridge: Sloan School of Management, Massachusetts Institute of Technology, 1971. Working paper \#535-71.

KOLB, D. Experiential learning. Englewood Cliffs: Prentice Hall, 1984.

LEONARD-BARTON, D. A. Methodology for case studies. synergistic use of a longitudinal single site with replicated multiple sites. In: HUBER, G. P.; VAN DE VEN, A. (Orgs.). Longitudinal Field research methods: studying processes of organizational change. London: Sage, 1995. p. 38-65.

MATURANA, H. Emoções e linguagem na educação e na política. Belo Horizonte: UFMG, 1998.

MATUS, C. Política, planejamento e governo. Brasília: IPEA, 1993.

MERRIAM, S. Qualitative research and case study applications in education. San Francisco: Jossey-Bass, 1998.

MORIN, E. O método iii: o conhecimento do conhecimento. Porto: EuropaAmérica, 1996.

MORGAN, G. Imagens da organização. São Paulo: Atlas, 2000.

NONAKA, I.; TAKEUCHI, H. Criação de conhecimento na empresa: como as empresas japonesas geram a dinâmica da inovação. Rio de Janeiro: Campus, 1997.

POLANYI, M. The tacit dimension. London: Routledge \& Kegan Paul, 1966.

SABAN, K. et al. Organizational learning: a critical component to new product development. Journal of Product and Brand Management, Bingley, v. 9, n. 2, p. 99-119, 2000.

SARAIVA, L. A. S. Mercantilização da cultura e dinâmica simbólica local: a indústria cultural em Itabira, Minas Gerais. 2009. 333f. Tese (Doutorado em Administração) - Faculdade de Ciências Econômicas, Universidade Federal de Minas Gerais, Belo Horizonte, Brasil, 2009.

SENGE, P. A quinta disciplina: arte, teoria e prática da organização de aprendizagem. São Paulo: Best Seller, 1990.. 
SILVA, J. F. Estudos de necessidades de informação dos setores industriais brasileiros: análise crítica e proposições. 2000. 96f. Dissertação (Mestrado em Ciência da Informação) - Escola de Ciência da Informação, Universidade Federal de Minas Gerais, Belo Horizonte, 2000.

SWERINGA, J.; WIERDSMA, A. Becoming a learning organization: beyond the learning curve. Wilmington: Addison-Wesley, 1995.

YIN, R. K. Estudo de caso: planejamento e métodos. 3. ed. Porto Alegre: Bookman, 2005. 